sap can be expressed from each portion merely by squeezing in the hand. The volume obtained after rubbing, as might be expected, is slightly less than that after freezing, for the shearing is less thorough. The concentrations in the two residue saps were approximately equal in this experiment, although in other experiments, those in the finger-rubbed fractions have been slightly below those in the frozen fractions. The maximum pressures used give no indication of the ease of expression of sap. From the fresh tissue, no sap was obtained below a dial reading of 4,000 $\mathrm{lb}$. per sq. inch hydraulic pressure, while with both the residues, most of the sap was expressed before the needle left the zero mark.

TABLE 3. EFFECT OF PREVIOUS TREATMENT OF RESIDUE ON SAP OBTAINABLE UNDER PRESSURE.

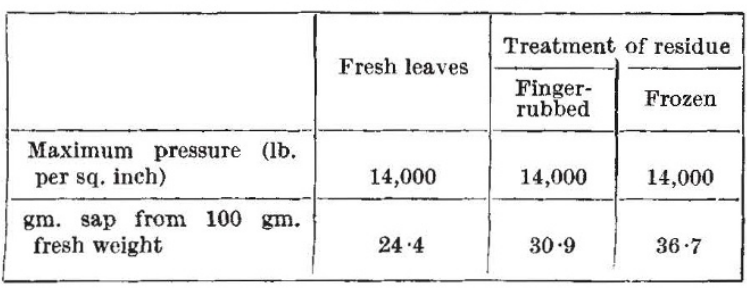

\begin{tabular}{|c|c|c|c|c|}
\hline & & \multirow{2}{*}{$\begin{array}{c}\text { Fresh } \\
\text { (hydraulic } \\
\text { pressing) }\end{array}$} & \multicolumn{2}{|c|}{ Residue treatment } \\
\hline & & & $\begin{array}{l}\text { Finger- } \\
\text { rubbed }\end{array}$ & Frozen \\
\hline \multirow{3}{*}{$\begin{array}{c}\text { Concentra- } \\
\text { tion (mgm. } \\
\text { per } 100 \\
\text { gm. water) }\end{array}$} & Calcium & 266 & 718 & 712 \\
\hline & Magnesium & $44 \cdot 0$ & $104 \cdot 7$ & $106 \cdot 6$ \\
\hline & Potassium & 275 & 599 & 604 \\
\hline
\end{tabular}

It is interesting to note that Audus has found that rubbing a leaf on both sides with a finger stall or merely bending the leaf increases respiration 2-3 fold.

If we are correct in the interpretation of the results, we can form approximate estimates of the concentrations of solutes in the vacuole and cyto. plasm respectively. The vacuolar estimate is obtained from the lowest concentration obtainable by direct pressing. This may be an over-estimate, for slight shearing forces will cause some cytoplasmic decomposition; for example, when brittle leaves are pressed in the hydraulic press, successive fractions of sap show diminishing concentration, due, we believe, to shearing forces developed in the leaf mass during the initial stages of compression. The action of such shearing forces is associated with the presence of chloroplasts in the expressed sap. If the vacuolar sap could be completely expressed the residue should, on decomposition, yield a sap representative of the cytoplasm, but incomplete vacuolar pressing will cause dilution of the cytoplasmic sap and an under. estimate of its concentration. In the leaves used in the experiment just described, the concentration in the cytoplasm must have been more than double that in the vacuole.

Methods used for the extraction of sap invariably include some process which we believe leads to destruction of the 'vitaid'. These processes include boiling $^{2}$, freezing, grinding ${ }^{10}$ and treatment with anæsthetics ${ }^{11}$. All saps obtained by these processes are, therefore, mixtures of vacuolar sap with that produced on decomposition of the vitaid. It will be necessary in the future, we think, to distinguish between the true (vacuolar) sap and that derived from the destruction of the cytoplasm.

\footnotetext{
${ }^{1}$ Dixon, H. H., and Atkins, W. R. G., Proc. Roy. Soc. Dub., 18, 422 (1913).

${ }^{2}$ Walter, H., Ber. deut. bot. Ges., 46, 539 (1938).

s Scarth, G. W., and Levitt, J., Plant Physiol., 12, 51 (1937).

- Stiles, W., "Introduction to Principles of Plant Physiology". (London, 1936).

s Jordan, Lloyd D., and Moran, T., Nature, 132, 515 (1933).

- Iljin, W. S., Bull. de l'assoc. Russe pour les recherches scientifiques $d$ Prague, 1 (VI). Sec. des sciences naturalles et mathímatiques. No. 4 (1934).

'Lepeschkin, W. W., Biodynamica, 19 (1936).

s Mason, T. G., and Phillis, E., Bot. Rev., 3, 47 (1937).

-Audus, L. J., Newo Phyt., 34, 386 (1935).

${ }^{10}$ Sayre, J. D., and Morris, V. H., Plant Physiol., 7, 261 (1932).

${ }^{11}$ Chibnall, A. C., J. Biol. Chem., 55, 333 (1923).
}

\title{
International Congress for Short Waves in Physics, Biology and Medicine, Vienna*
}

Pro ROF. H. THIRRING, in an address made during the opening ceremony of the Short Wave Congress held in Vienna on July 12-17, referred to the many fields of application of Hertzian waves in research, medicine and radio technology. These fields are to some extent interdependent, and there are in particular medical and biophysical problems which require the collaboration of biologists, physicists and radio-engineers if they are to be solved satisfactorily. Thirring pointed specially to the urgent problem of dosage measurement in short wave therapy and to the fundamental scientific question of the mode of biological action of short waves : specific or thermal. These problems occupied a prominent position in the Congress, and, together with purely physical papers, will form the substance of the

* Internationaler Kongress für Kurzwellen in Physik, Biologie und Medizin. Referate und Mitteilungen. (Wien: Brüder Hollinck, 1937). present report; the review articles in the various sections and the fifty or so papers in the medical section will not be dealt with. (Number in brackets in each heading indicates the number of papers presented.)

(1) Production of ultra-short waves (11). Most of the papers dealt with retarding field or magnetron circuits devised for production of the shortest waves; the most interesting perhaps was the $14 \mathrm{~cm}$. wave retarding field generator with resonant cavity as frequency stabilizer, demonstrated by Dällenbach, Alderding and Kleinsteuber. The demonstration showed the remarkable frequency stability attained and the modulation of the $14 \mathrm{~cm}$. wave. Another retarding field system was described by Meng and Potapenko, who have construeted exceedingly symmetrical micro-tubes for high-order oscillations of wave-length $\sim 1 \mathrm{~cm}$. McArthur described a new 
magnetron, of single (water-cooled) anode type with permanent magnet and concentric tube transmission line, giving 10 watts at $\lambda 4.8 \mathrm{~cm}$. Groskowsky and Ryzko discussed the increased efficiency obtainable with 4-anode magnetron tubes when the usual tungsten cathode is replaced by oxide-coated nickel. The Okabe electron beam magnetron was described. by Joji Ito.

(2) Transmission: Ionosphere research (12). Van der Pol sketched a theory of propagation of ultrashort waves over the earth, starting from the Maxwell equations, with proper boundary conditions; he showed that $7 \mathrm{~m}$. waves must diffract considerably beyond the horizon, with a strong attenuation which is due to absorption by the ground. Southworth discussed transmission in pipes or cylindrical rods of dielectric. For a hollow metal pipe the diameter must be at least $0.58 \lambda$. The resonant cavity is a special case of this system, and may be used as a frequency determining unit or as an impedance matching device, and perhaps as a new means of 'irradiating' laboratory specimens.

Six of these papers dealt with the ionosphere, beginning with a review by Zenneck. Burkard discussed the information concerning the ionosphere and its diurnal and seasonal variations obtained from a statistical treatment of amateur radio reports-as many as 10,000 per month. Reports for the summers 1934 and 1935 (sunspot minimum-single reflection, presumably from $F_{2}$ ) gave $240 \mathrm{~km}$. as the mean height of the layer. Ito Yoji described ionosphere studies during the total eclipse of June 19, 1936, when there was found 47 per cent decrease in electron density in $F_{1}$, but practically no effect on $F_{2}$. Fuchs described a method of determining the absolute temperature in the ionosphere, obtaining the values $F_{1}>400^{\circ}, F_{2}>1,400^{\circ} \mathrm{K}$., so that the daily division into the two layers is presumably due to gas-thermal effects. Hals described the discovery of the Hals. Störmer echoes, and Fuchs provided an interpretation, as an ultra-violet ionization phenomenon of the upper atmosphere.

(3) Absorption and dispersion in chemical systems (4). Potapenko described a new modification of the Drude-Coolidge method for determination of $\varepsilon^{\prime}$ and $\varepsilon^{\prime \prime}$; together with Keutner, he has used the method for measurement on monohydric alcohols and glycerol, finding, as others have found, approximate agreement with the Debye theory. Williams has measured the absorption of $1.25 \mathrm{~cm}$. waves by ammonia gas, the ray being diffracted from an échelette grating after passage through the gas, and the intensity being determined with a crystal detector.

(4) Dielectric properties of tissues : heat production in tissues and tissue models (4). The papers on this subject brought out clearly the large number of factors which must be taken into account in considering the possibility of selective heating of tissues by ultra-short waves. Given fixed values of $\varepsilon$ (dielectric constant) and $x$ (specific conductivity) for the various parts of a body, the matter is relatively simple; if, however, both $\varepsilon$ and $x$ are strongly dependent on frequency and on temperature, the calculation of the optimal wave-length for selective heating of a certain tissue becomes impossible without complete experimental dispersion curves for all the tissues concerned. In regard to $x$, Schaefer and Rajewsky have now extended their measurements on blood to several other tissues, while an admirable series of measurements by K. Osswald shows the dependance of both $\varepsilon$ and $x$ on frequency even in the ultra high-frequency region. A further complicating factor may be the very large effect of field intensity on dipole losses in solutions of zwitterions, observed by Schmelzer in the case of tetra- $n$-butylammonium bromide in benzene, although it is not yet known what proportion of the observed high-frequency conductivity of tissues is due to substances of this tyce.

This complexity in the physical properties of heterogeneous systems makes it important to obtain empirical information concerning selective heating by experiments with 'models', however approximate such information may be. Pätzold described measure. ments of the relative heating of juxtaposed layers of fat and muscle in the condenser field at $\lambda 6 \mathrm{~m}$. and $1 \mathrm{~m}$., the results of which are in substantial agreement with those calculated from Osswald's data. He has also measured the relative heating of layers of salt solutions in a solenoidal field as a function of position, wave-length and number of coil windings, and further considered the possibility of applying ultra high-frequency energy by 'irradiation', on the basis of Halbwertschicht determinations on salt solutions and tissues at $\lambda .4 \cdot 3 \mathrm{~m}$.

(5) Physics and chemistry of possible specific (non. thermal) effects (17). It soon became clear that 'nonthermal' effects might be placed in several categories : (a) Specific electrical and mechanical effects, the existence of which, in principle, can scarcely be doubted, resulting in chain configuration of suspended particles, in decreased degree of dispersion, change in viscosity, etc., dependent on field strength and type of field but not on frequency. These effects were admirably discussed by Krasny-Ergen. (b) Possible specific chemical and biochemical effects, the existence of which has not yet been satisfactorily demonstrated, although frequently asserted. These were discussed by Königer, who suggested possible 'resonance' absorption effects, in the sense of Romanoff's theory. Bateman and Rosenberg discussed the physical conditions which have to be satisfied for the experimental elimination of thermal effects. (c) Possible non-thermal physiological effects on cell suspensions, when thermal effects can be avoided by use of proper experimental conditions. According to Hasché, Leunig and Loch, the field has no effect on B. coli and Staph. pyoceanus aureus under most conditions of wave-length, intensity and type of suspension medium, although a few inconsistent observations have been made at $\lambda 3.5 \mathrm{~m}$.; similar negative results were obtained by Ruete with $B$. coli and several moulds, and by Malov, with Drosophila (mutation rate and lethal action). The observations of Roth (development of exposed seeds), of Wertheim ('biopositive' effects on yeast) and of Schweinburg (on rabies virus), with their less satisfactory control of heating, do not necessarily contradict these negative results. $(d)$ Effects on large bodies: 'specific' effects opposite to 'heating' effects. Most of the observed physiological effects belong in this category; they could be the result of $(a)$ or $(b)$, or else-more probably-merely thermal effects of a special kind, due to the peculiar distribution of temperature gradients in the body which results from exposure to the field. None of the many experiments of this type described at the Congress contributed essentially to the solution of the problem.

(6) Measurement of absorbed energy in ultra-short wave therapy (9). The difficulties of a satisfactory measurement of 'intensity' (watts absorbed/sec.) were enumerated by several contributors, and a number 
of modifications of known procedures were described. In particular, Mittelmann has used a method involving the preliminary determination of the effective resistance of the circuit with a secondary transmitter and valve voltmeter, followed by measurement of $I$ or $E$ during treatment with thermo-cross and dynamometer. Riesinger measures the total anode dissipation of his transmitter with ammeter and volt. meter, and the heat dissipation with a photo-cell and a reflecting bimetal strip fixed to the anode, the difference representing the high-frequency energy generated. It seems, however, uncertain whether this arrangement can be used, as Riesinger claims, as a dose intensity indicator. Schwarz suggested two rapid methods : first, determination of 'spread' of the resonance curve by means of variable condenser and Braun tube; secondly, measurement of true field across the object by small electrometer electrodes mounted in the condenser plates. The papers on the subject gave the impression, however, that the problem is still far from being solved.

J. B. Bateman.

\section{The Science of Archives in South Africa*}

$\mathrm{S}^{\mathrm{T}}$ UDY and work connected with archives have been recognized as a science, and a scientific system of keeping archives has been evolved; while not only is a high standard of attainment and a wide range of knowledge of scientific method and results demanded of the archivist, but also in certain European countries provision has been made for his technical training.

Archives constitute a fundamental source of historical information, and hence the introduction of the moving picture-the cinematograph film and the 'talkies' have, in the problem of their conservation, forced on the attention of the archivist a number of practical questions, the method of dealing with which has yet to be determined on scientific lines.

In South Africa, prior to the date of the Union, the Cape Province gave attention to this subject more than half a century ago, and the Transvaal since about 1902. In 1919 the Union Government took the first serious step in co-ordinating the archives of the four provinces.

The administration of Union and Provincial Archives was centralized in a chief archivist, and by legislation of 1922 Union and Provincial archive depots were created, the former at the seat of government of the Union, and the latter at the seat of the Provincial administration. The centres thus are in Cape Town, Pretoria, Pietermaritzburg and Bloem. fontein, each in charge of an archivist, and the whole administration centralized in the chief archivist. This system secures uniformity of administration, arrangement, classification, inventorying, methods of preservation and general care. It has resulted in straightforward administrative efficiency, and experience has taught that it is the only satisfactory method. Experts in archive economy the world over endorse this system.

The Archives Department is a young branch of the Public Service of the Union of South Africa. Its advance, unspectacular but steady, during the last decade or so, was marked by a persistent claim to recognition as an integral part of the Government machinery and the necessity for its personnel to be men with a certain standard of education and an aptitude for the work.

An archives depot is not static, and must increase in quantity and quality as the years pass. The

* Substance of the presidential address to the South African Association for the Advancement of Science, at the Windhoek meeting on July 5, 1937, by Lieut.-Colonel C. Graham Botha, chief arehivist of the Union of South Africa.
Department was conceived, no doubt, as a branch of the service with great possibilities. Its growth was slow at first, and to some extent stunted because it had to overcome many prejudices. When it was given a place in the Government machinery, it had to live down the prevalent conception that it was a warehouse for the storage of records with someone in charge to keep them from deterioration and permit their consultation when necessary. It had to have a proper home and the right kind of vitamins in its food to allow it to develop. But this stripling of a department struggled on, facing all the obstacles which beset it.

South Africa had the advantage of studying the systems of similar institutions of older and more experienced countries. It avoided the pitfalls made by them in the past and took the best from each country and adapted this to suit the conditions in South Africa. Other sections of the British Commonwealth of Nations afterwards gave attention to the organization of their national records, such as the Commonwealth of Australia and the Dominion of New Zealand. The most recent recruit is the Colony of Southern Rhodesia, which created an Archives Department by legislation a few years ago. From the three countries, inquiries came to South Africa regarding the system of keeping archives which was being adopted.

Within the last ten years, the archives at Capo Town, Pietermaritzburg and Bloemfontein have been transferred to their buildings with up-to-date equipment and protective devices at a cost of many tens of thousands of pounds. Steps are being taken to provide a separate building at Pretoria, which will house the Provincial archives and contain the records of the Union Government, when old enough for the transfer so laid down by law.

To illustrate the growth of this branch of the service during the last eighteen years, personnel and salary expenditure have increased from a staff of five and an expenditure of $£ 2,800$ in 1919 , to a staff of 42 and an expenditure of $£ 11,000$ in 1937. The number of researchers and visitors and volumes con. sulted during the last five years indicates a steady and encouraging increase.

The system for the arrangement and classification of the archives in South Africa is that recognized in Europe, and referred to as the 'principe des fonds', in which the system of classification is based on the department of origin. Experience has shown that this is the only sound one. 